\title{
Characterization and Utilization of Tannin Extract for the Selective Adsorption of Ni (II) Ions from Water
}

\author{
Priya Meethale Kunnambath and Santhi Thirumalaisamy \\ Department of Chemistry, Karpagam University, Coimbatore, Tamil Nadu 641021, India \\ Correspondence should be addressed to Santhi Thirumalaisamy; ssnilasri@yahoo.co.in
}

Received 10 November 2014; Accepted 1 December 2014

Academic Editor: Vijay K. Thakur

Copyright (C) 2015 P. Meethale Kunnambath and S. Thirumalaisamy. This is an open access article distributed under the Creative Commons Attribution License, which permits unrestricted use, distribution, and reproduction in any medium, provided the original work is properly cited.

\begin{abstract}
The current paper studies the preparation of a new tannin gel from Acacia nilotica for water purification and waste water remediation. Design of experiments is used for optimizing the tannin gel using tannin extract (Taguchi method) with formaldehyde in the assistance of microwave (TGAN) by the help of iodine number. The feasible combinations were tested in the removal of nickel from simulated and river water. In this study, the effect of adsorbent dosage, $\mathrm{pH}$, and initial metal concentration on $\mathrm{Ni}$ (II) biosorption on modified Acacia nilotica tannin gel (TGAN) was investigated. Tannin gel was characterized by SEM, FTIR, XRD, and EDAX. The kinetic data was tested using pseudo-first-order, pseudo-second-order, and intraparticle diffusion model. The results suggested that the pseudo-second-order model $\left(R^{2}>0.998\right)$ was the best choice among all the kinetic models describing the adsorption behavior of Ni (II) onto TGAN. Langmuir, Freundlich, Temkin, and Dubinin-Radushkevich adsorption models were used to represent the equilibrium data. The best interpretation for the experimental data was given by the Langmuir isotherm and the maximum adsorption capacity $250 \mathrm{mg} \mathrm{g}^{-1}$ of $\mathrm{Ni}$ (II) was obtained at pH 5.04 at $296 \mathrm{~K}$. Adsorption of Ni (II) onto TGAN is confirmed qualitatively by the use of atomic absorption spectroscopy. The BOD and COD values are considerably reduced after adsorption.
\end{abstract}

\section{Introduction}

Heavy metal ions such as $\mathrm{Pb}, \mathrm{Cd}, \mathrm{Hg}, \mathrm{Cr}, \mathrm{Ni}, \mathrm{Zn}$, and $\mathrm{Cu}$ are nonbiodegradable, toxic, and carcinogenic even at very low concentrations and, hence, usually pose a serious threat to the environmental and public health [1]. Many industries discharge heavy metals such as lead, cadmium, copper, nickel, and zinc in their wastewaters [2]. Metals such as copper and nickel are known to be essential to plants, humans, and animals, but they can also have adverse effects if their availability in water exceeds certain threshold values. Nickel is a toxic heavy metal that is widely used in silver refineries, electroplating, zinc base casting, and storage battery industries [3]. The chronic toxicity of nickel to humans and the environment has been well documented. For example, high concentration of nickel causes cancer of lungs, nose, and bone.

For this reason, the advanced treatment processes such as chemical reduction, ion exchange, reverse osmosis, electro dialysis and activated carbon adsorption are generally used. Since the cost of these processes is rather expensive, the use of agricultural residues or industrial by-product having biological activities has been received with considerable attention. In recent years, a number of agricultural materials such as sugar cane waste [4], grain [5], palm fibres [6], Annona squamosa seed [7], coir pith [3], and granular Muntingia calabura [8] have been reported for the removal of toxic metals from aqueous solutions using adsorption.

Tannins, natural biomass containing multiple adjacent hydroxyl groups and exhibiting specific affinity to metal ions, can probably be used as alternative, effective, and efficient adsorbents for the recovery of metal ions. During the last years, the interest on biomaterials and specifically in tannins was growing. The term tannins cover many families of chemical compounds. Traditionally, they have been used for tanning animal skins, hence their name, but one also finds several of them used as water treatment agents. Their natural origin is as secondary metabolites of plants [9] occurring 
in the bark, fruit, leaves, and so forth. While Acacia and Schinopsis bark constitute the principal source of tannins for the leather industry, the bark of other nontropical trees such as Quercus ilex, suber, and robur, Castanea, and Pinus can also be tannin-rich. Agricultural by-products have high volume, low value, and underutilized lignocellulosic biomaterials and contain high levels of cellulose, hemicellulose, and lignin.

However, tannins are water-soluble compounds; thus, when they are used directly as an adsorbent for recovery of metals from aqueous systems, they have the disadvantage of being leached by water. To overcome this disadvantage, attempts have been made to immobilize tannins onto various water-insoluble matrices [10].

More recently, tannin has emerged as a potential alternative for the removal of heavy metals from aqueous solutions $[11,12]$. Tannins are natural plant extracts and contain high content of multiple adjacent phenolic hydroxyls in their molecules, and thus they have strong chelating ability towards many heavy metal ions including $\mathrm{Cr}$ (III), $\mathrm{Pb}$ (II), Hg (II), $\mathrm{Cd}$ (II), and Au (II). Biosorption, a biological method of environmental control, can be an alternative to conventional waste-treatment facilities [13]. The concept of biosorption refers to the passive sorption and/or complexation of metal ions by biomass [14]. As tannins contain an abundant amount of adjacent hydroxyl groups more than the adsorbent-like carbon in their molecules, they form chelates with metals. Since tannins are water-soluble compounds, they often need to be immobilized onto water-insoluble matrixes such as cellulose [15], hydrotalcite [16], and collagen fiber [17].

Acacia nilotica is native to Africa and the Indian subcontinent and it grows throughout the drier parts of India. In Haryana, Acacia nilotica based agro forestry systems reduce the yield of wheat. Many researchers synthesized adsorbents from commercial tannins and applied them to remove heavy metals from waste water, such as uranium [18], chromium [19], copper [20], and lead [21]. The objective of this study is to systematically examine adsorption mechanisms, adsorption isotherms, adsorption kinetics, and properties of a tannin gel adsorbent prepared from leaves of Acacia nilotica (TGAN) for removal of $\mathrm{Ni}$ (II) ions from aqueous solutions.

\section{Experimental Section}

2.1. Materials. All the chemicals used in this study were of analytical reagent grade and were utilized without further purification. The leaves of Acacia nilotica were obtained from the agricultural farm in Coimbatore district (Tamil Nadu). They were washed with distilled water to remove dirt, dust, and surface impurities. Washed leaves are then air-dried in room temperature and powdered in a grinder.

2.2. Preparation of Tannin Extracts. $100 \mathrm{~g}$ of Acacia nilotica leaves powder was cleaned and it was put in $600 \mathrm{~mL}$ of distilled water. Then, $5 \mathrm{~g}$ of $\mathrm{NaOH}$ was added and the mixture was stirred in magnetic stirrer at $90^{\circ} \mathrm{C}$ for 1 hour. Solids were separated by filtration and liquid fraction was dried in oven $\left(65^{\circ} \mathrm{C}\right)$ overnight. Resultant was considered as tannin resin (TR). Total phenol content of tannin content was calculated. Design of experiments was carried out by using SPSS 14.0 for Windows [22] and L16 matrix by Taguchi method [23]. Tannin gel was prepared according to this by taking 4 variables. Up to 16 different combinations regarding three variables were attempted. The feasible combinations were just nine of them; the rest did not jellify.

2.3. Preparation of Tannin Gel (TGAN). Tannin gels were prepared according to the basis of Nakano et al. [22]. Five grams of tannin extract were dissolved in $32 \mathrm{~mL}$ of $0.125 \mathrm{~mol} \mathrm{~L}^{-1}$ $\mathrm{NaOH}$ and $30 \mathrm{~mL}$ of distilled water at $80^{\circ} \mathrm{C}$. When mixture was homogeneous, certain amount of aldehyde was added and reaction was kept at the same temperature for $8 \mathrm{~h}$ until polymerization was considered completed. Then, the apparent gummy product led to complete evaporation of water remains and was dried in oven $\left(65^{\circ} \mathrm{C}\right)$ overnight. After drying, tannin rigid gels were crushed and sieved to produce tiny diameters. They were washed successively with distilled water and $0.01 \mathrm{~mol} / \mathrm{L} \mathrm{HNO}_{3}$ to remove unreached sodium hydroxide. Finally, the adsorbent was dried again in oven at $80^{\circ} \mathrm{C}$.

2.4. Preparation of Stock Solution. Samples of nickel sulphate hexahydrate $\left(\mathrm{NiSO} \cdot 6 \mathrm{H}_{2} \mathrm{O}\right)$ and other chemicals were obtained from Aluva, Edayar (Spectrum Reagents and Chemicals Pvt. Ltd.). A Stock solution of $1000 \mathrm{mg} / \mathrm{L}$ was prepared by dissolving accurately weighed amounts of nickel sulphate hexahydrate in doses of $1000 \mathrm{~mL}$ double-distilled water. Working chromium and nickel solutions were prepared just before use by appropriate dilutions of stock solution.

2.5. Batch Mode Experiments. Batch adsorption experiments were carried out to evaluate the effects of $\mathrm{pH}$, contact time, initial concentration, and adsorption dosage on adsorbed amounts. Tests were carried out to evaluate adsorption kinetics, adsorption isotherms, and desorption of $\mathrm{Ni}$ (II) on TGAN. In all sets of experiments, a fixed volume of single metal ion solutions of $50 \mathrm{~mL}$ of various concentrations $\left(50,100,150\right.$, and $\left.200 \mathrm{mg} \mathrm{L}^{-1}\right)$ and, for binary metal solution (BMS), $50 \mathrm{~mL}$ volume of BMS solution with $25 \mathrm{~mL}$ of $50 \mathrm{mg} \mathrm{L}^{-1}$ concentration of working metal and $25 \mathrm{~mL}$ of $\mathrm{Ni}$ (II) of various concentrations $\left(10,20,30,40\right.$, and $50 \mathrm{~mL}^{-1}$ ) were taken in a conical flask. $\mathrm{pH}$ adjustment was fulfilled by adding $0.1 \mathrm{M} \mathrm{HCl}$ or $0.1 \mathrm{M} \mathrm{NaOH}$ into the solutions with known initial metal concentrations. Batch adsorption experiments were conducted in $250 \mathrm{~mL}$ stoppered flasks containing $200 \mathrm{mg}$ of adsorbent and $50 \mathrm{~mL}$ of metal solutions with different concentrations $(25-200 \mathrm{mg} / \mathrm{L})$ at the optimum solution $\mathrm{pH}$. The flasks were agitated using a mechanical orbital shaker and maintained at room temperature for $2 \mathrm{~h}$ at a fixed shaking speed of $120 \mathrm{rpm}$ until the equilibrium was reached. The suspensions were filtered and metal concentrations in the supernatant solutions were measured using a Shimzadu UV-vis spectrophotometer. Supernatants were analyzed by flame atomic absorption spectrophotometer (AAS) for the qualitative analysis. From the initial and final 
concentrations, percentage removal can be calculated by the use of the following formula:

$$
\% \text { of removal }=\frac{C_{0}-C_{F}}{C_{0}} \times 100,
$$

where $C_{0}$ is the initial concentration of Ni (II) ions in $\mathrm{mg} / \mathrm{L}$ and $C_{F}$ is the final concentration of $\mathrm{Ni}$ (II) ions in $\mathrm{mg} / \mathrm{L}$. The results obtained in batch mode were used to calculate the equilibrium metal uptake capacity. The amounts of uptake and Ni (II) ions by TGAN in the equilibrium $\left(q_{e}\right)$ were calculated by the following mass-balance relationship:

$$
q_{e}=\frac{V\left(C_{0}-C_{F}\right)}{W},
$$

where $q_{e}$ is the equilibrium uptake capacity in $\mathrm{mg} / \mathrm{g}, V$ is the sample volume in liters, $C_{0}$ is the initial metal ion concentration in $\mathrm{mg} / \mathrm{L}, C_{F}$ the equilibrium metal ion concentration in $\mathrm{mg} / \mathrm{L}$, and $W$ is the dry weight of adsorbent in grams.

2.6. BOD and COD Analysis. Biochemical oxygen demand or $\mathrm{BOD}$ is the amount of dissolved oxygen needed by aerobic biological organisms in a body of water to break down organic material present in a given water sample at certain temperature over a specific time period.

COD or chemical oxygen demand is the total measurement of all chemicals (organic and inorganic) in the water/waste water. Which are commonly found carbon but it varies based on the industrial process and nature of the raw materials used. These parameters (BOD and COD) are usually associated with sewage, not with drinking water. The ratio of $\mathrm{COD} / \mathrm{BOD}$ describes organic toxicity because $\mathrm{COD}$ is a measure of total (toxic and nontoxic) organic and BOD is a measure of nontoxic organic load. The aim of any waste water treatment should be to reduce this ratio.

\section{Result and Discussion}

3.1. Optimization of TGAN Preparation Conditions. In order to optimize the preparation conditions of the TGAN, Taguchi experimental design method was used. The variables shown in Table 1 are used for making the orthogonal array. Iodine is considered as probe molecule for assessing the adsorption capacity of adsorbents for solutes of molecular sizes less than $10 \AA$. Iodine number was normally listed as specification parameter for TGAN. Iodine number and the yield of gel prepared under optimum conditions were $583.16(\mathrm{mg} / \mathrm{g})$ and $65.08 \%$, respectively. The TGAN was used in the characterization analysis and adsorption experiments which were prepared under optimum conditions [23].

3.2. XRD Analysis. Adsorption reaction may lead to changes in molecular and crystalline structure of the adsorbent and hence an understanding of the molecular and crystalline structures of the adsorbent and the resulting changes thereof would provide valuable information regarding adsorption reaction. Hence, XRD patterns of the adsorbent before and after adsorption of $\mathrm{Ni}$ (II) ions have been studied. As a
TABLE 1: Designs and levels of Taguchi method.

\begin{tabular}{lccccc}
\hline \multirow{2}{*}{ Independent variables } & \multirow{2}{*}{ Symbol } & \multicolumn{5}{c}{ Range and levels } \\
& & 1 & 2 & 3 & 4 \\
\hline Polymerization time (h) & A & 8 & 12 & 16 & 18 \\
Acetaldehyde dose $(\mathrm{mL})$ & B & 2 & 0 & 4 & 6 \\
Formaldehyde dosage $(\mathrm{mL})$ & C & 0 & 2 & 4 & 6 \\
Tannin extract $(\mathrm{g})$ & D & 5 & 7 & 9 & 11 \\
\hline
\end{tabular}

representative case, the XRD patterns of TGAN before and after treatment with Ni (II) ions are shown in Figure 1. $y$ axis represents the intensity. The results indicated that the diffraction profiles of TGAN before and after adsorption of $\mathrm{Ni}$ (II) ions exhibited broad peaks and the absence of a sharp peak revealed a predominantly amorphous structure; the broad peak seems to appear at around $2 \theta=42,53,35$ and $29^{\circ}$ is confirmed as a tannin gel which was similar to the peak of crystalline carbonaceous structure such as graphite [24]. Small peaks correspond to impurities naturally present in tannins. It is evident from the figure that the XRD pattern of TGAN loaded with $\mathrm{Ni}$ (II) ions exhibits no variation in the crystal structure and this suggests that the Ni (II) ions might diffuse into micropores and sorbs mostly by physisorption without altering the structure of the adsorbent. From the $\mathrm{XRD}$ analysis for the adsorbent (TGAN), we concluded that the tannin gel preparation was completed.

3.3. FTIR Analysis. Surface functional groups were detected by Fourier transform infrared (FTIR) spectroscope from the scanning range $\left(4000 \mathrm{~cm}^{-1}-400 \mathrm{~cm}^{-1}\right)$ and elemental analysis was performed using an elemental analysis. An FTIR spectrum for TGAN before and after adsorption of nickel ions shows in Figure 2 and the wide range of $3200-3600 \mathrm{~cm}^{-1}$ show that phenolic $-\mathrm{OH}$ groups are intensively present within the nature of raw tannin. Generally, wide bands in the range of $3550-3100 \mathrm{~cm}^{-1}$ correspond to $-\mathrm{OH}$ bridging groups in all systems and, here, bands between 3304 and $3361 \mathrm{~cm}^{-1}$ and show the presence of the same groups. The small peaks in the region of $2854-2927 \mathrm{~cm}^{-1}$ are associated with the methylene $\left(-\mathrm{CH}_{2}-\right)$ bridges of the tannin resin. The peaks at 1058 $1105 \mathrm{~cm}^{-1}$ in the spectrum are due to C-O stretching and $\mathrm{C}-\mathrm{H}$ deformation. The absorption bands between $1631 \mathrm{~cm}^{-1}$ and $1452 \mathrm{~cm}^{-1}$ are characteristic of the elongation of the aromatic $-\mathrm{C}-\mathrm{H}-$ bonds. The peak around $1190 \mathrm{~cm}^{-1}$ is due to the presence of ether $(\mathrm{C}-\mathrm{O}-\mathrm{C})$ groups. The deformation vibration of the carbon-carbon bonds in the phenolic groups absorbs in the region of $1500-1400 \mathrm{~cm}^{-1}$ [25].

3.4. Scanning Electron Microscope. The surface structure of the adsorbents TGAN before and after adsorption was analyzed by scanning electron microscopy (SEM). SEM images for the samples of TGAN before and after metal ion adsorptions are shown in Figures 3 and 4, respectively. As expected from the textural analysis, the sample TGAN exhibits a rough porous surface. The images obtained with the gel foam shows that strong modifications of the surface occur 

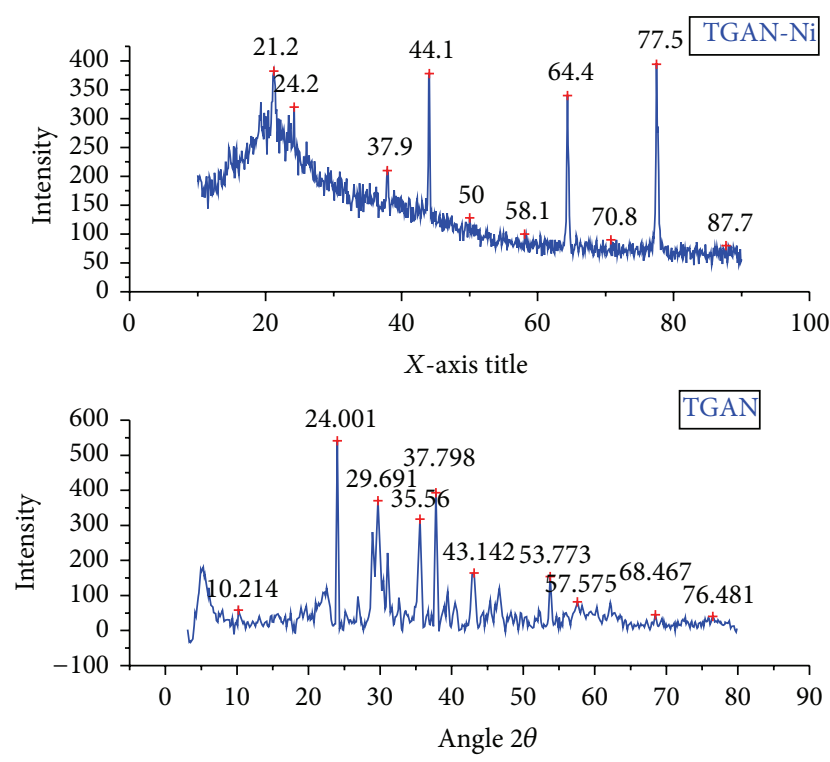

FIGURE 1: XRD analysis of TGAN and TGAN-Ni.

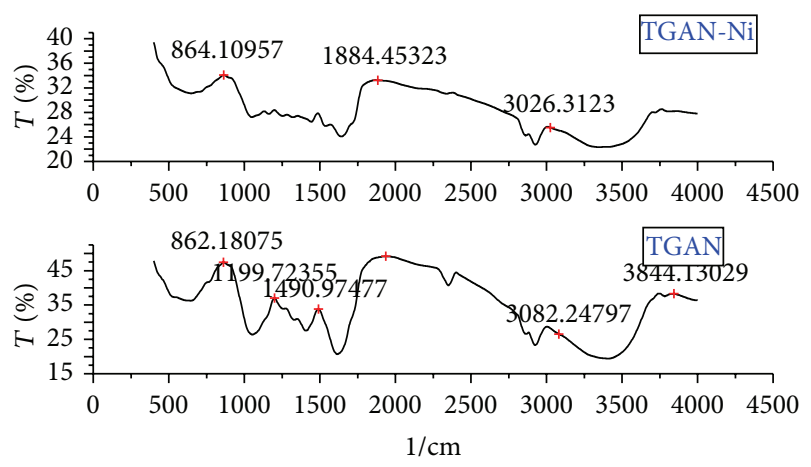

FIgUre 2: FTIR analysis of TGAN and TGAN-Ni.

during the activation process. Ripples and dimples appear on the cell wall surfaces during activation and a consequent increase of the surface area is obtained. The pores are different after adsorption as its size cannot visible clearly because it is completely filed with the metal ions.

3.5. Energy Dispersive X-Ray Spectroscopic Analysis (EDAX). The adsorption efficiency of TGAN was confirmed by EDAX analysis results. The EDAX spectrum of TGAN shows elements present in tannin gel. The EDAX spectra of TGAN and TGAN-Ni are shown in Figure 4. This micrograph reveals the appearance of $\mathrm{Ni}$ (II) ion on the surface of TGAN. EDAX spectra showed the presence of $\mathrm{O}, \mathrm{C}, \mathrm{Ca}, \mathrm{K}$, and $\mathrm{Zn}$ in the adsorbent. These have been known as the principle elements of the adsorbents. These are summarized in Table 2.

3.6. Effect of $p H$ on Metal Uptake. Figure 5 shows the effect of $\mathrm{pH}$ on the metal adsorption by TGAN. Adsorption of $\mathrm{Ni}$ (II) increases due to the fact that the dissociation of active groups on the TGAN surface was also increased with $\mathrm{pH}$, that is, when $\mathrm{pH}$ increases from 2 to 7 , probably due
TABLE 2: Data for the elements presented in TGAN-Ni.

\begin{tabular}{lccc}
\hline Elements & Intensity & Mass $\%$ & Atomic \% \\
\hline TGAN & & & \\
CK & 0.277 & 94.05 & 95.63 \\
OK & 0.525 & 5.58 & 4.26 \\
CaK & 3.69 & 0.37 & 0.11 \\
TOTAL & & $\mathbf{1 0 0}$ & $\mathbf{1 0 0}$ \\
TGAN-Ni & & & \\
C K & 1.0436 & 53.20 & 62.00 \\
O K & 0.0509 & 41.15 & 36.01 \\
Mg K & 0.0716 & 0.42 & 0.24 \\
Si K & 0.8962 & 0.43 & 0.21 \\
P K & 1.2944 & 0.48 & 0.22 \\
S K & 0.9463 & 0.44 & 0.19 \\
Ca K & 0.9812 & 1.58 & 0.55 \\
Fe K & 0.7901 & 1.76 & 0.44 \\
Ni K & 0.7872 & 0.54 & 0.13 \\
Total & & $\mathbf{1 0 0}$ & $\mathbf{1 0 0}$ \\
\hline
\end{tabular}

to the acidic dissociation of the phenolic hydroxyl groups of tannin, resulting in strongly complex ability with metal ions. The maximum uptake for $\mathrm{Ni}$ (II) is at $\mathrm{pH}$ 5.04. As though, the initial $\mathrm{pH}$ was fixed at $\mathrm{pH} 5$ in all sorption. At $\mathrm{pH}$ above the zero point charge $(\mathrm{pHzpc}=5.12)$, the negatively charged carboxylate ions (-COOA) have strong coordinative affinity toward positively charged metal ions and also, at high $\mathrm{pH}$ values higher than 5.12, these metal ions in the precipitated because of the high concentration at these $\mathrm{pH}$ values could not be performed well. Furthermore, the phenolic hydroxyl groups of the TGAN would more readily be oxidized, making it impractical to apply this approach above $\mathrm{pH} 8.0$ [26]. The electrostatic forces of attraction allow the carboxylate ions to capture the metal ions through surface complexation, forming chelate complexes [27]. The degree of surface complexation increases with increasing $\mathrm{pH}$. Hence, maximum adsorption capacity occurs at $\mathrm{pH} 5.04$ for $\mathrm{Ni}$ (II). At $\mathrm{pH} 5.04$, adsorption of $\mathrm{Ni}$ (II) on tannin gel was found to be $76.5 \%$.

3.7. Effect of Initial Metal Ion Concentration. Figure 6 shows the experimental results of adsorption of $\mathrm{Ni}$ (II) ions on the TGAN at various concentrations $(25,50,75,100,125$, 150,175 , and 200). The result shows that the percentage of adsorption decreased with the increase in initial nickel ion concentration. This is due to the fact that, at low concentration, the ration of initial number of nickel ion to the available surface area is low and subsequently the effect of adsorption is independent of initial concentration. This is due to the fact that, by increasing the concentration of metal ions in solution, the availability of metal at the interface also increases, thus increasing the amount of adsorption. When the surface active sites are fully covered, the extent of adsorption reaches a limit resulting in saturated adsorption [28]. 


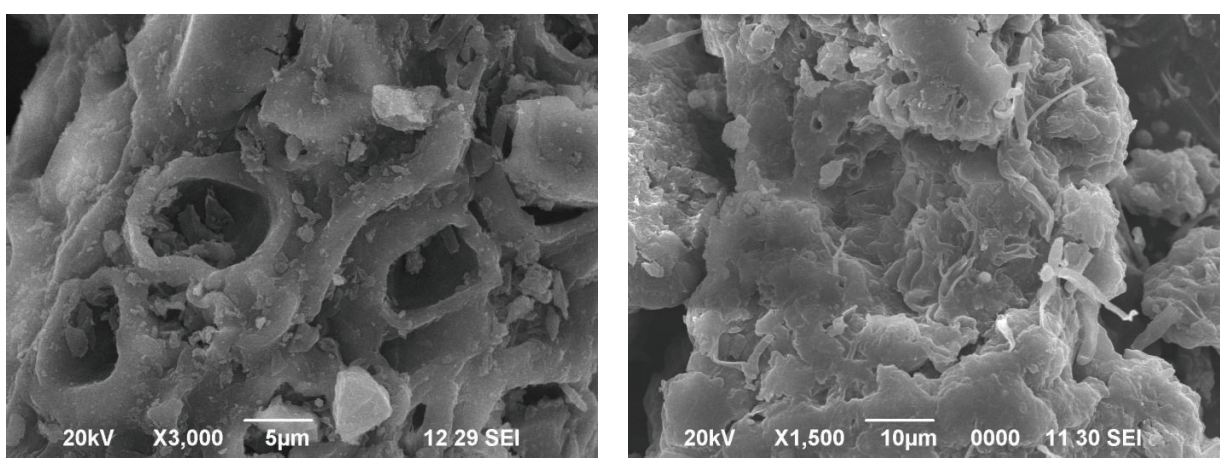

FIGURE 3: SEM images of TGAN and TGAN-Ni.
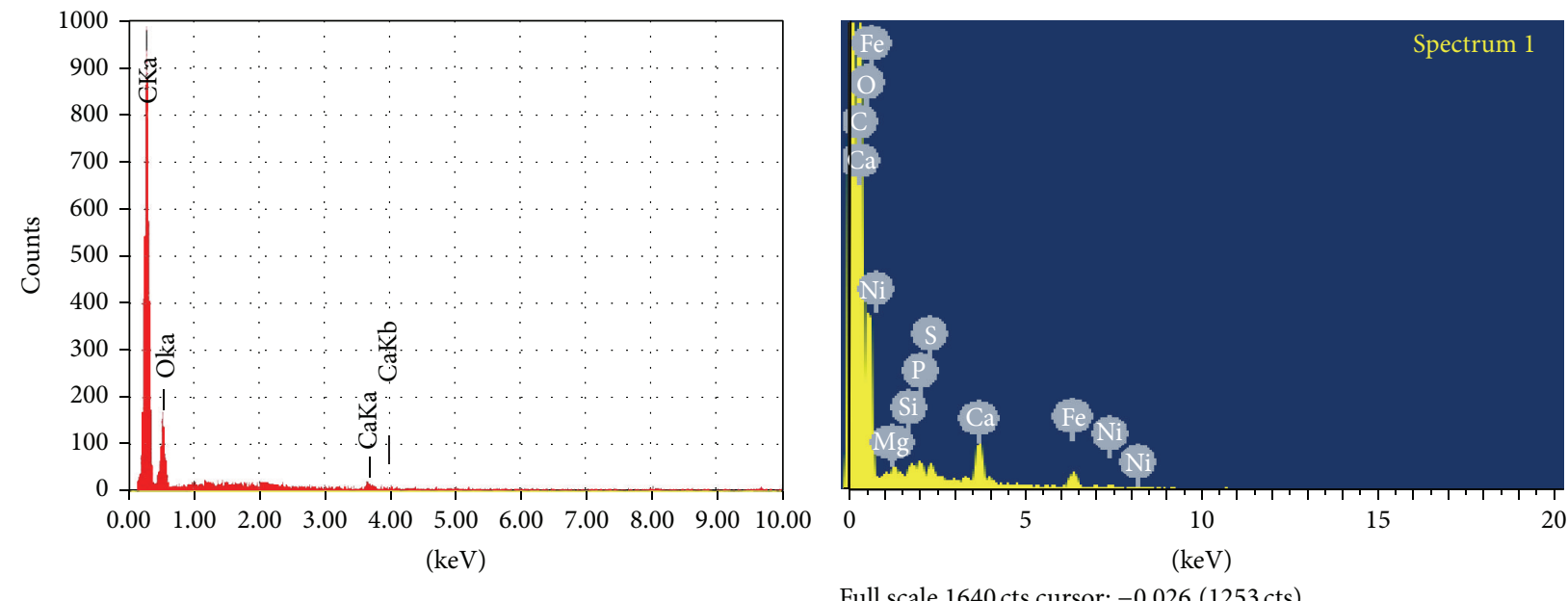

FIgURE 4: EDAX analysis of TGAN and TGAN-Ni.

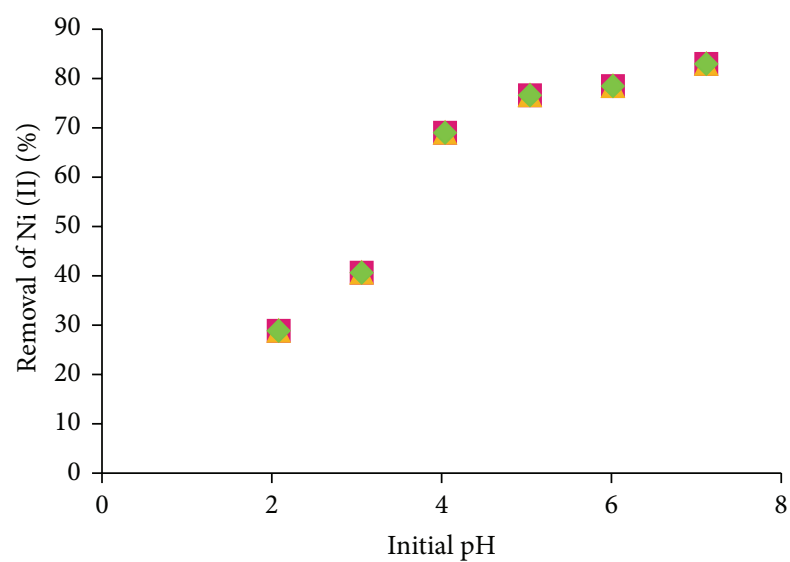

FIGURE 5: Effect of solution $\mathrm{pH}$ on the adsorption of $\mathrm{Ni}$ (II) ions on TGAN.

3.8. Effect of Contact Time. The percentage removal was found to increase with increasing contact time (Figure 7) and then it became almost stable, denoting attainment of equilibrium as so the maximum value at $35 \mathrm{~min}$ for $\mathrm{Ni}$ (II) ions. Figure 7 shows the effect of time for the adsorption

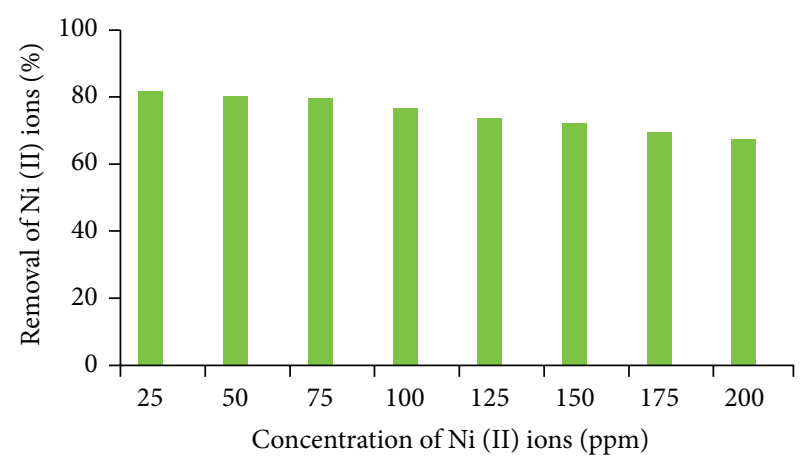

FIGURE 6: Effect of metal ion concentration on the adsorption of $\mathrm{Ni}$ (II) ions by TGAN.

of Ni (II) onto TGAN. This may be due to the fact that once a certain amount of $\mathrm{Ni}$ (II) ions gets doped onto these adsorbents within a given time, no more doping occurs afterward; that is, the doping level might have been reached. That is, initially, all adsorbent sites were vacant and the solute concentration was high, and, after that period, only a very low increase in the metal update was observed because there are few surface active sites on TGAN. From these results, it 


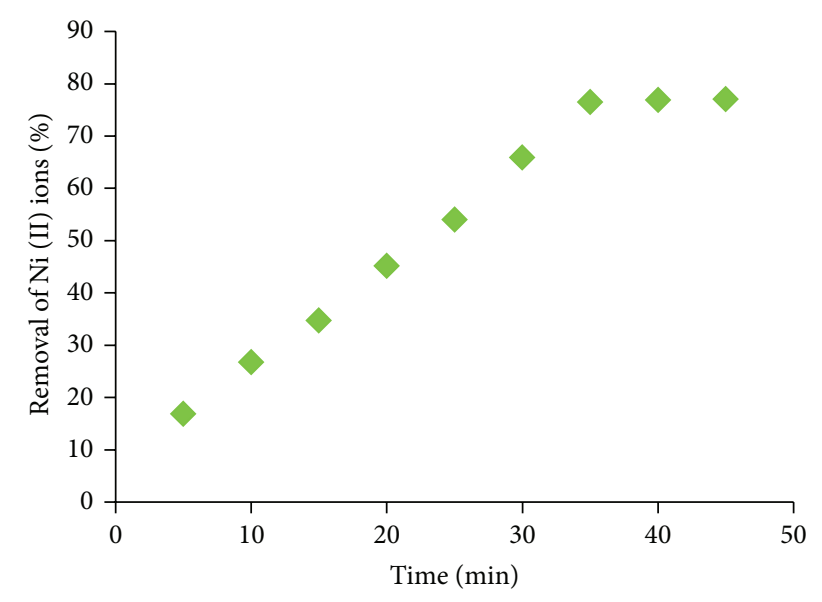

FIgURE 7: Effect of contact time on the adsorption of Ni (II) ions onto TGAN.

is suggested that only a minimum time is required for the adsorption of metal ion from tannin gel prepared by Acacia nilotica leaves.

3.9. Effect of Adsorbent Dose. The dependence of Ni (II) adsorption on dose was studied by varying the amount of adsorbents from 0.05 to $1 \mathrm{~g} / \mathrm{L}$, by keeping the other parameters ( $\mathrm{pH}$, contact time, and initial metals concentration) constant. From Figure 8, it could be observed that removal efficiency of the adsorbent generally increased with increasing dose. The increase in removal efficiency with increasing adsorbent dose is probably due to the greater adsorbent surface area and pore volume available at higher adsorbent dose providing more functional groups and active adsorption sites that result in a higher removable percentage. When the surface active sites are fully covered, the extent of adsorption reaches a limit resulting in saturated adsorption. The drop in adsorption capacity is due to the sites remaining unsaturated during the adsorption process. Thus, further experiments were carried out using $200 \mathrm{mg}$ of adsorbent per $50 \mathrm{~mL}$ of $\mathrm{Ni}$ (II) ion solutions, as it exhibits appreciable removal capacity, for the optimization of adsorption parameters. The maximum adsorption capacity of $\mathrm{Ni}$ (II) on to Acacia nilotica surface was estimated to be $250 \mathrm{mg} / \mathrm{L}$ at $100 \mathrm{ppm}$.

3.10. Application of Adsorption Isotherm Models for the Metal Adsorption. Adsorption isotherm is the most important information which indicates how the adsorbate molecules distribute between the liquid phase and the solid phase when adsorption process reaches equilibrium state. When the system is at equilibrium, this is important to determine the maximum sorption capacity of TGAN towards metal solution. Equilibrium data are a basic requirement for the design of adsorption systems and adsorption models, which are used for the mathematical description of the adsorption equilibrium of the metal ion by the adsorbent. The results obtained for adsorption of $\mathrm{Ni}$ (II) ions were analyzed by use of well-known models given by the Langmuir, Freundlich, Temkin, and Dubinin-Radushkevich, adsorption isotherm

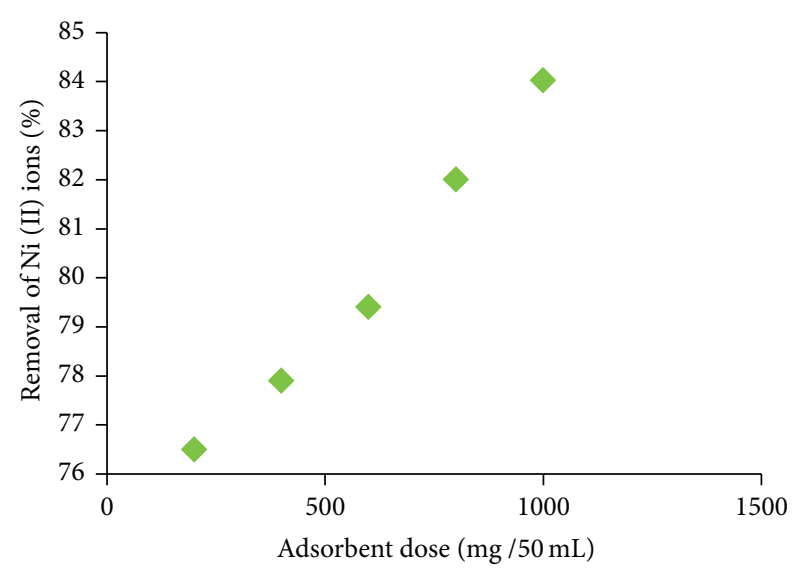

FIGURE 8: Effect of adsorbent dose on the adsorption of $\mathrm{Ni}$ (II) ions by TGAN.

models [29-31]. For the sorption isotherms, initial metal ion concentration was varied whereas solution $\mathrm{pH}$ and amount of adsorbent were held constant. The sorption isotherm for $\mathrm{Ni}$ (II) ions was obtained for TGAN at solution $\mathrm{pH} 5.04$. Consider

$$
\begin{aligned}
\frac{C_{e}}{q_{e}} & =\frac{1}{Q_{e} K_{L}}+\frac{1}{Q_{e}} C_{e}, \\
\log q_{e} & =\log K_{F}+\frac{1}{n} \log C_{e}, \\
q_{e} & =B \ln A+B \ln C_{e}, \\
q_{e} & =Q_{m} \exp \left(-K \varepsilon^{2}\right),
\end{aligned}
$$

where $C_{e}$ is the $\mathrm{Ni}$ (II) ion concentration in the solution $(\mathrm{mg} / \mathrm{L}), q_{e}$ is the Ni (II) concentrations in the solid adsorbent (mg/g), $Q_{m}$ is the maximum adsorption capacity ( $\mathrm{mg} / \mathrm{g}$ ), $K_{f}$ is a constant related to the adsorption capacity $\left(\mathrm{mg} / \mathrm{L}^{1 / n}\right.$, $\left./ \mathrm{mg}^{1 / n}\right), 1 / n$ is adsorption intensity, $b$ is a constant related to the energy of adsorption $(\mathrm{L} / \mathrm{g}), n$ is a constant related to the energy of adsorption, $\alpha(\mathrm{L} / \mathrm{g})$ is Temkin constant representing adsorbent-adsorbate interactions and $\beta\left(\mathrm{mgL}^{-1}\right)$ is another constant related to adsorption heat, and $\varepsilon$ is the Polanyi constant. The adsorption isotherm parameters for all the four isotherm models are calculated and the values are summarized in Table 3 .

It can be seen that the Langmuir isotherm fits the data better than Freundlich; D-R and Temkin isotherms with the linear regression coefficients, $R^{2}$, TGAN, have a homogeneous surface for adsorption of metal ions. This high $R^{2}$ value indicates that the adsorption of nickel ions onto TGAN takes place as monolayer adsorption on a surface that is homogeneous in surface affinity. The Langmuir isotherm equation is therefore expected to best represent the equilibrium adsorption data. The $R^{2}$ values for the Langmuir model are closer to unity than those for the other isotherm models for TGAN $\left(R^{2}=0.9980\right)$. 
TABLE 3: Adsorption isotherm parameters for the adsorption of $\mathrm{Ni}$ (II) ions.

\begin{tabular}{lcc}
\hline Isotherms models & Variables & TGAN-Ni \\
\hline \multirow{3}{*}{ Langmuir } & $b$ & 0.037 \\
& $R^{2}$ & 0.994 \\
& $Q_{m}$ & 250 \\
\hline \multirow{3}{*}{ Freundlich } & $K_{f}\left(\mathrm{mg} \mathrm{g}^{-1}\right)$ & 2.511 \\
& $R^{2}$ & 0.985 \\
& $n$ & 0.434 \\
\hline \multirow{3}{*}{ Temkin } & $\beta$ & 2.814 \\
& $R^{2}$ & 0.977 \\
& $\alpha$ & 762.3 \\
\hline \multirow{4}{*}{ Dubinin-Radushkevich } & $R^{2}$ & 0.948 \\
& $Q_{m}\left(\mathrm{mg} \mathrm{g}^{-1}\right)$ & 0.456 \\
& $E\left(\mathrm{~kJ} \mathrm{moL}^{-1}\right)$ & 0.088 \\
& $K\left(\times 10^{-5} \mathrm{~mol}^{2} \mathrm{~kJ}^{-2}\right)$ & 64.88 \\
\hline
\end{tabular}

3.11. Kinetics Study for Ni (II) onto TGAN. The study of adsorption kinetics describes the solute uptake rate and evidently this rate controls the residence time of the adsorbate at the solid solution interface. The rate of adsorption can be computed from the kinetic study. In order to find out the mechanism of adsorption and potential rate controlling steps such as chemical reaction, diffusion control, and mass transport process, kinetic models have been used to test experimental data from the adsorption of $\mathrm{Ni}$ (II) ions onto TGAN. These kinetic models were analyzed using pseudofirst-order, pseudo-second-order, and intraparticle diffusion models which were, respectively, presented as follows [3235]:

$$
\begin{gathered}
\ln \left(q_{e}-q_{t}\right)=\ln q_{e}-k_{1} t, \\
\frac{t}{q_{t}}=\frac{1}{k_{2} q_{e}^{2}}+\frac{1}{q_{e}} t, \\
q_{t}=k_{i p} t^{1 / 2}+C,
\end{gathered}
$$

where $t$ is the contact time of adsorption experiment (min); $q_{e}(\mathrm{mg} / \mathrm{g})$ and $q_{t}(\mathrm{mg} / \mathrm{g})$ are, respectively, the adsorption capacity at equilibrium and at any time $t ; k_{1}(1 / \mathrm{min}), k_{2}$ (g/mg min), $\alpha$ (mg/g min), $\beta$ (g/mg), and $k_{i p}\left(\mathrm{mg} / \mathrm{g} \mathrm{min}{ }^{1 / 2}\right)$ are the rate constants for these models, respectively. The correlation coefficients for all the four kinetic models were calculated and the results are shown in Table 4.

The adsorption process of $\mathrm{Ni}$ (II) ions can be well fitted by use of the pseudo-second-order rate constant for TGAN. The linear regression coefficient value $R^{2}=0.998$ for $\mathrm{Ni}$ (II) obtained for pseudo-second-order kinetics was closer to unity than the $R^{2}$ value 0.934 for $\mathrm{Ni}$ (II) ions for first-order kinetics. This indicates that adsorption of $\mathrm{Ni}$ (II) ions by TGAN follows pseudo-second-order kinetics.

3.12. Atomic Absorption Spectroscopy and BOD and COD Analysis. Atomic absorption spectrophotometer analysis was done for the TGAN gel treated with metal solutions
TABLE 4: The correlation coefficients of kinetic parameters for the adsorption of $\mathrm{Ni}$ (II) ions onto TGAN.

\begin{tabular}{lcc}
\hline Kinetic models & Variables & TGAN-Ni \\
\hline \multirow{3}{*}{ Pseudo-first-order } & $K_{1}$ & 0.0552 \\
& $q_{e}$ & 169.82 \\
& $R^{2}$ & 0.0934 \\
\hline \multirow{3}{*}{ Pseudo-second-order } & $h$ & 10.2 \\
& $Q_{e}$ & 13.89 \\
& $K_{2}$ & 0.0147 \\
Intraparticular diffusion & $R^{2}$ & 0.988 \\
& $K_{d}$ & 3.150 \\
& $C$ & 5.145 \\
& $R^{2}$ & 0.906 \\
\hline
\end{tabular}

TABLE 5: Analytical values of TGAN before and after Ni (II) adsorption.

\begin{tabular}{lccc}
\hline Samples & BOD & COD & AAS $(\mathrm{mg} / \mathrm{L})$ \\
\hline Before adsorption & 90.78 & 245 & 0.57 \\
After adsorption & 3.25 & 9.05 & 0.29 \\
\hline
\end{tabular}

nickel. Comparatively, nickel showed better adsorption using TGAN. For tannin gel, nickel content before adsorption onto TGAN is $10.30 \mathrm{mg} / \mathrm{L}$ and is decreased to $5.50 \mathrm{mg} / \mathrm{L}$. The values of BOD of water before and after adsorption of $\mathrm{Ni}$ (II) and the AAS results are given in the Table 5. This shows that the values decrease from before to after as though it explains the efficiency of the TGAN produced from Acacia nilotica leaves for $\mathrm{Ni}$ (II) adsorption.

3.13. Desorption. Desorption studies were carried out using different $\mathrm{HCl}$ concentration solutions $(0.05,0.1,0.2$, and 0.3$)$. To keep the cost of biosorption process down, our results indicate that TGAN biosorbent could be used repeatedly in $\mathrm{Ni}$ (II) biosorption, the repeated availability of the adsorbents after adsorption. Figure 9 shows the desorption ability and recycling ability. Desorption cycles are crucial to illustrate the stability and potential recovery of the adsorbents. Desorption by $0.2 \mathrm{~N} \mathrm{HCl}$ solution easily occurring might be related to the intensive competition between $\mathrm{H}^{+}$ions (introduced by $\mathrm{HCl}$ solution) and metal ions on the active sites. Meanwhile, at low $\mathrm{pH}$ value, the complexation between the adsorbent and metal ions was destroyed $[36,37]$. These results illustrated that the TGAN possesses the ability of regeneration and repeated use in heavy metal removal with slight losses in their initial adsorption capacities.

After desorption, the adsorbents were further used for adsorption of $\mathrm{Ni}$ (II) ions. The percentage removal of $\mathrm{Ni}$ (II) ion was found to be $59.64 \%$ for TGAN at $\mathrm{pH}$ 8. The increase in removal of $\mathrm{Ni}$ (II) ions at $\mathrm{pH} 9$ may be because of precipitation of metal ions in alkaline medium rather than adsorption.

\section{Conclusion}

The present study showed that tannin gel prepared from Acacia nilotica leaf can be an effective adsorbent for the 


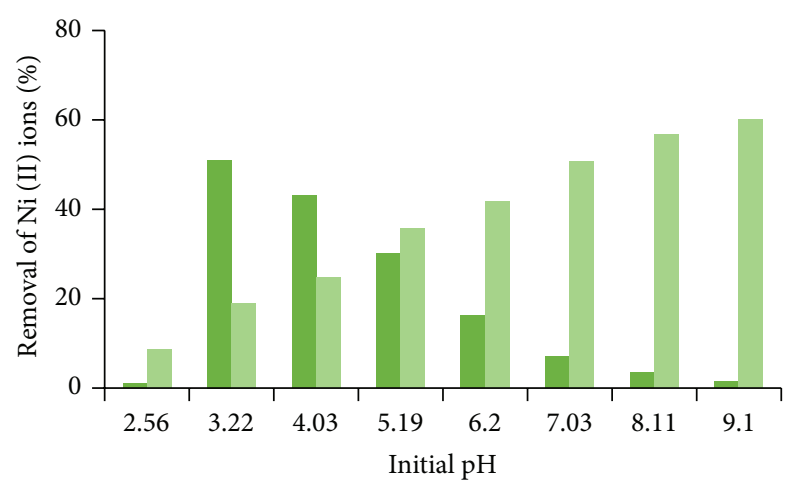

FIGURE 9: Desorption and recycling of Ni (II) ions onto TGAN.

removal of Ni (II) from aqueous solution. The adsorption process is dependent on the contact time, $\mathrm{pH}$, and dosage and initial metal ion concentration. The Langmuir isotherm model gave a better fit than other isotherms for interpreting the adsorption phenomenon. The Ni (II) adsorption system followed a pseudo-second-order kinetic model. The removal efficiency increased with an increase in agitation time and adsorbent dosage. By applying the kinetic models to the experimental data, it was found that the kinetics $\mathrm{Ni}$ (II) ions adsorption onto TGAN was followed by the pseudo-secondorder rate equation. The amount of metal is reduced and so it is proved qualitatively using atomic absorption spectroscopy. Results of kinetic studies demonstrated that the Ni adsorption was rapid and efficient. Desorption of Ni (II) from the spent adsorbent was achieved with $0.2 \mathrm{~N} \mathrm{HCl}$. The use of Acacia nilotica as an adsorbent seems to be an economical and worthwhile alternative compared to conventional methods for the removal of $\mathrm{Ni}$ (II) from aqueous solution.

\section{Conflict of Interests}

The authors have declared that no conflict of interests exists.

\section{References}

[1] C. Liu, R. Bai, and Q. San Ly, "Selective removal of copper and lead ions by diethylenetriamine-functionalized adsorbent: behaviors and mechanisms," Water Research, vol. 42, no. 6-7, pp. 1511-1522, 2008.

[2] K. K. Krishnani, X. Meng, C. Christodoulatos, and V. M. Boddu, "Biosorption mechanism of nine different heavy metals onto biomatrix from rice husk," Journal of Hazardous Materials, vol. 153, no. 3, pp. 1222-1234, 2008.

[3] K. Kadirvelu and C. Namasivayam, "Agricultural by-product as metal adsorbent: sorption of lead(II) from aqueous solution onto coirpith carbon," Environmental Technology, vol. 21, no. 10, pp. 1091-1097, 2000.

[4] V. K. Gupta and I. Ali, "Removal of lead and chromium from wastewater using bagasse fly ash-a sugar industry waste," Journal of Colloid and Interface Science, vol. 271, no. 2, pp. 321328, 2004.

[5] K. S. Low, C. K. Lee, and S. C. Liew, "Sorption of cadmium and lead from aqueous solutions by spent grain," Process Biochemistry, vol. 36, no. 1-2, pp. 59-64, 2000.
[6] K. S. Low, C. K. Lee, and K. P. Lee, "Sorption of copper by dyetreated oil-palm fibres," Bioresource Technology, vol. 44, no. 2, pp. 109-112, 1993.

[7] T. Santhi, S. Manonmani, and T. Smitha, "Kinetics and isotherm studies on cationic dyes adsorption onto annona squmosa seed activated carbon," International Journal of Engineering Science and Technology, vol. 2, no. 3, pp. 287-295, 2010.

[8] T. Santhi, S. Manonmani, and S. Ravi, "Uptake of cationic dyes from aqueous solution by biosorption onto granular Muntingia calabura," E-Journal of Chemistry, vol. 6, no. 3, pp. 737-742, 2009.

[9] P. Schofield, D. M. Mbugua, and A. N. Pell, "Analysis of condensed tannins: a review," Animal Feed Science and Technology, vol. 91, no. 1, pp. 21-40, 2001.

[10] X. Liao, Z. Lu, M. Zhang, X. Liu, and B. Shi, "Adsorption of $\mathrm{Cu}(\mathrm{II})$ from aqueous solutions by tannins immobilized on collagen," Journal of Chemical Technology and Biotechnology, vol. 79, no. 4, pp. 335-342, 2004.

[11] B. H. Cruz, J. M. Díaz-Cruz, C. Ariño, R. Tauler, and M. Esteban, "Multivariate curve resolution of polarographic data applied to the study of the copper-binding ability of tannic acid," Analytica Chimica Acta, vol. 424, no. 2, pp. 203-209, 2000.

[12] H.-W. Ma, X.-P. Liao, X. Liu, and B. Shi, "Recovery of platinum(IV) and palladium(II) by bayberry tannin immobilized collagen fiber membrane from water solution," Journal of Membrane Science, vol. 278, no. 1-2, pp. 373-380, 2006.

[13] O. S. Amuda, A. A. Giwa, and I. A. Bello, "Removal of heavy metal from industrial wastewater using modified activated coconut shell carbon," Biochemical Engineering Journal, vol. 36, no. 2, pp. 174-181, 2007.

[14] C. Mack, B. Wilhelmi, J. R. Duncan, and J. E. Burgess, "Biosorption of precious metals," Biotechnology Advances, vol. 25, no. 3, pp. 264-271, 2007.

[15] A. Nakajima and T. Sakaguchi, "Recovery of uranium by tannins immobilized onagarose," Journal of Chemical Technology and Biotechnology, vol. 40, no. 4, pp. 223-232, 1987.

[16] I. Chibata, T. Tosa, T. Mori, T. Watanabe, and N. Sakata, "Immobilized tannin-a novel adsorbent for protein and metal ion," Enzyme and Microbial Technology, vol. 8, no. 3, pp.130-136, 1986.

[17] X. Huang, L. Jiao, X. Liao, and B. Shi, "Adsorptive removal of as(III) from aqueous solution by $\mathrm{Zr}(\mathrm{IV})$-loaded collagen fiber," Industrial and Engineering Chemistry Research, vol. 47, no. 15, pp. 5623-5628, 2008.

[18] T. Sakaguchi and A. Nakajima, "Accumulation of uranium by immobilized persimmon tannin," Separation Science and Technology, vol. 29, no. 2, pp. 205-221, 1994.

[19] W. Li, Y. Tang, Y. Zeng, Z. Tong, D. Liang, and W. Cui, "Adsorption behavior of $\mathrm{Cr}(\mathrm{VI})$ ions on tannin-immobilized activated clay," Chemical Engineering Journal, vol. 193-194, pp. 88-95, 2012.

[20] I. A. Sengil and M. Ozacar, "Biosorption of $\mathrm{Cu}(\mathrm{II})$ from aqueous solutions by mimosa tannin gel," Journal of Hazardous Materials, vol. 157, no. 2-3, pp. 277-285, 2008.

[21] X.-M. Zhan and X. Zhao, "Mechanism of lead adsorption from aqueous solutions using an adsorbent synthesized from natural condensed tannin," Water Research, vol. 37, no. 16, pp. 39053912, 2003.

[22] Y. Nakano, K. Takeshita, and T. Tsutsumi, "Adsorption mechanism of hexavalent chromium by redox within condensedtannin gel," Water Research, vol. 35, no. 2, pp. 496-500, 2001. 
[23] M. Makeswari and T. Santhi, "Removal of malachite green dye from aqueous solutions onto microwave assisted zinc chloride chemical activated Epicarp of Ricinus communis," Journal of Water Resource and Protection, vol. 5, pp. 222-238, 2013.

[24] M. Makeswari and T. Santhi, "Tannin gel derived from Leaves of Ricinus Communis as an adsorbent for the Removal of $\mathrm{Cu}$ (II) and $\mathrm{Ni}$ (II) ions from aqueous solution," International Journal of Modern Engineering Research (IJMER), vol. 3, pp. 3255-3266, 2013.

[25] M. Yurtsever and I. A. Şengil, "Biosorption of $\mathrm{Pb}(\mathrm{II})$ ions by modified quebracho tannin resin," Journal of Hazardous Materials, vol. 163, no. 1, pp. 58-64, 2009.

[26] X. Liao, L. Li, and B. Shi, "Adsorption recovery of thorium(IV) by Myrica rubra tannin and larch tannin immobilized onto collagen fibres," Journal of Radioanalytical and Nuclear Chemistry, vol. 260, no. 3, pp. 619-625, 2004.

[27] T. Santhi, S. Manonmani, and T. Smitha, "Removal of malachite green from aqueous solution by activated carbon prepared from the epicarp of Ricinus communis by adsorption," Journal of Hazardous Materials, vol. 179, no. 1-3, pp. 178-186, 2010.

[28] M. Mahramanlioglu, I. Kizilcikli, and I. O. Bicer, "Adsorption of fluoride from aqueous solution by acid treated spent bleaching earth," Journal of Fluorine Chemistry, vol. 115, no. 1, pp. 41-47, 2002.

[29] I. Langmuir, "The adsorption of gases on plane surfaces of glass, mica and platinum," The Journal of the American Chemical Society, vol. 40, no. 9, pp. 1361-1403, 1918.

[30] H. Freundlich, "Über die Adsorption in Lösungen (Adsorption in solution)," Zeitschrift für Physikalische Chemie, vol. 57, pp. 384-470, 1906.

[31] I. A. W. Tan, B. H. Hameed, and A. L. Ahmad, "Equilibrium and kinetic studies on basic dye adsorption by oil palm fibre activated carbon," Chemical Engineering Journal, vol. 127, pp. 111-119, 2011.

[32] M. M. Dubinin, E. D. Zaverina, and L. V. Radushkevich, "Sorption and structure of activated carbons, I. Adsorption of organic vapours," Zhurnal Fizicheskoi Khimii, vol. 21, pp. 1351$1362,1947$.

[33] Y. S. Ho and G. McKay, "Sorption of dye from aqueous solution by peat," Chemical Engineering Journal, vol. 70, no. 2, pp. 115124, 1998.

[34] Y. S. Ho and G. Mckay, "Kinetic models for the sorption of dye from aqueous solution by wood," Journal of Environmental Science Health Part B: Process Safety and Environmental Protection, vol. 76, pp. 184-185, 1998.

[35] W. J. Weber Jr. and J. C. Morris, "Kinetics of adsorption on carbon from solution," Journal of Sanitary Engineering Division, vol. 89, no. 2, pp. 31-60, 1963.

[36] M.-R. Huang, H.-J. Lu, and X.-G. Li, "Efficient multicyclic sorption and desorption of lead ions on facilely prepared poly $(m$-phenylenediamine) particles with extremely strong chemoresistance," Journal of Colloid and Interface Science, vol. 313, no. 1, pp. 72-79, 2007.

[37] Y. Ren, N. Li, J. Feng et al., "Adsorption of $\mathrm{Pb}(\mathrm{II})$ and $\mathrm{Cu}(\mathrm{II})$ from aqueous solution on magnetic porous ferrospinel $\mathrm{MnFe}_{2} \mathrm{O}_{4}$," Journal of Colloid and Interface Science, vol. 367, no. 1, pp. 415421, 2012. 

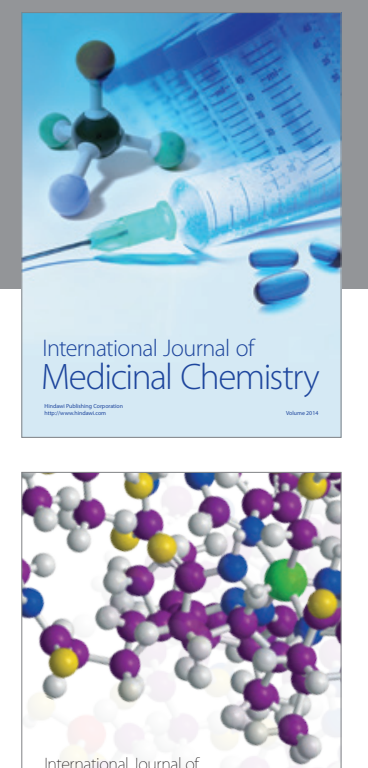

\section{Carbohydrate} Chemistry

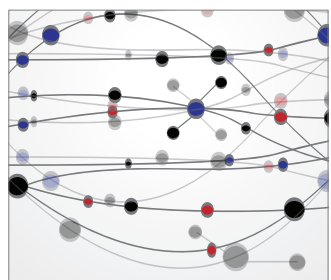

The Scientific World Journal
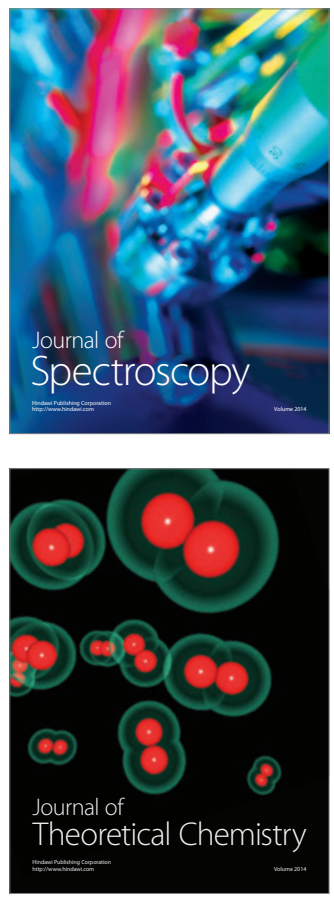
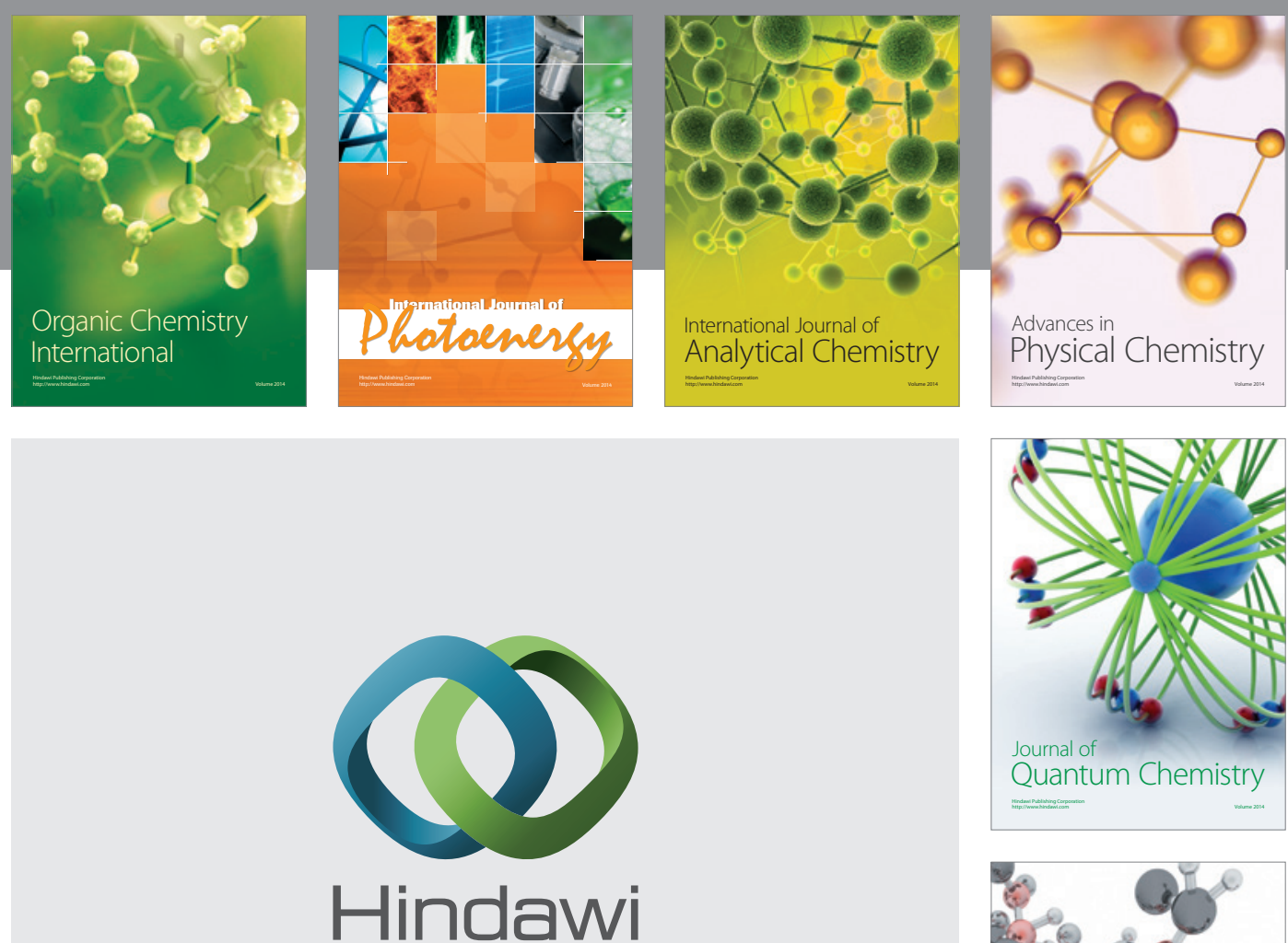

Submit your manuscripts at

http://www.hindawi.com

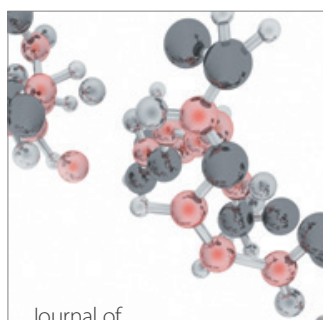

Analytical Methods

in Chemistry

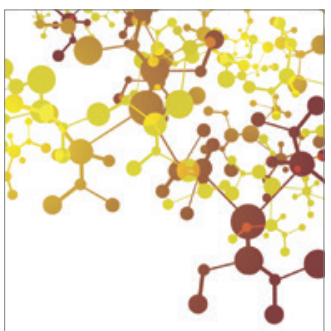

Journal of

Applied Chemistry

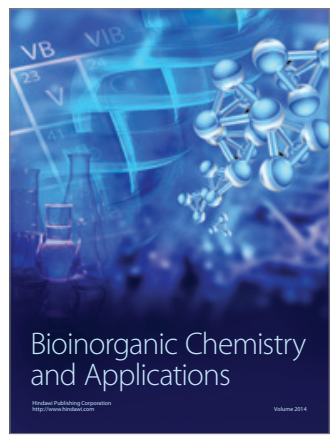

Inorganic Chemistry
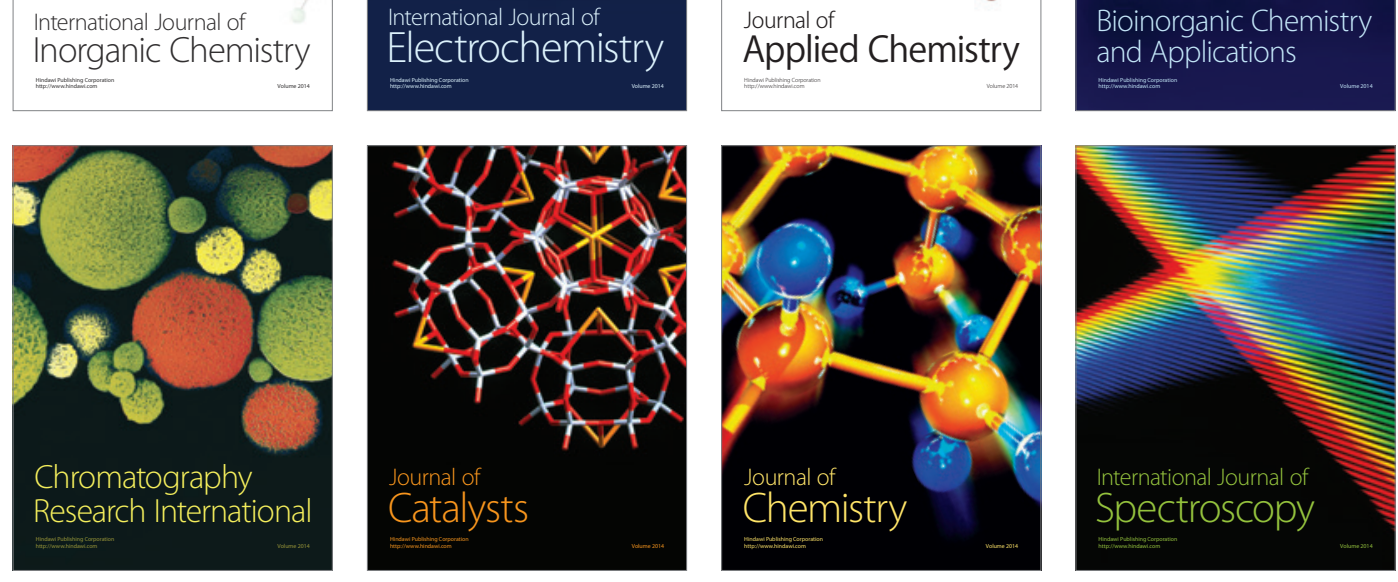